\title{
Life Satisfaction and Its Associated Factors - A Correlational Study Among Carpenters
}

\author{
Anu Gangwar ${ }^{1 *}$ and U. V. Kiran ${ }^{2}$ \\ 'M.Sc. Student, Department of Human Development \& Family Studies School for Home Sciences, Babasaheb Bhimrao \\ Ambedkar University, Lucknow - 226025, Uttar Pradesh, India, anugangwar31@gmail.com \\ 2Professor, Department of Human Development \& Family Studies School for Home Sciences, Babasaheb Bhimrao \\ Ambedkar University, Lucknow - 226025, Uttar Pradesh, India
}

\begin{abstract}
Life satisfaction is the evaluation of a individual makes how properly his/her life is going overall. Life satisfaction is a multidimensional conception it is directly connected to the physical, social, economic and psychological aspects of anyone. Objective: The present study is to have a look at the existence delight among carpenters from Lucknow city. Methods: A Self-Structured Questionnaire and Satisfaction with Life Scale (SWLS) with the aid of Diener, Emmons, Larsen \& Griffin (1985) was used to measure life style pleasure among carpenters. 120 male carpenters were selected for the study as sample. Snowball sampling technique was used in the present study. Result: Results showed a significant impact of age on life satisfaction among carpenters, life satisfaction of carpenters was found to be decreasing with increase in age. Of all the age groups, 40-50 years age group carpenters were found more satisfied with their work. Type of work was also found to be influencing the life satisfaction among carpenters. Training programmes are to be conducted for carpenters to cope with the work stress and also the physical and psychological risks associated with them.
\end{abstract}

Keywords: Carpenters, Life Satisfaction, SWLS

\section{Introduction}

Life happiness is an evaluation of individual emotions positively or negatively about their life. It can be considered as mind-set and emotional responses for the work project as nicely as the physical and social condition of the job place. Life fulfilment can be described as the high-quality feeling about an individual's job ensuing from a contrast of its quality. A individual with excessive degree of job satisfaction holds positive feeling about their life, whilst a person who is disappointed holds bad emotions about the life ${ }^{1}$.

Life satisfaction is one of the very necessary elements of subjective wellbeing. Life satisfaction is wonderful from affective appraisal in which it is found to be more cognitively than emotionally driven. Life pleasure can be assessed particular to a specific area of life or globally. Satisfaction is a kingdom of mind. It is an evaluative appraisal of something. The time period refers to both 'contentment' and 'enjoyment'. As such it covers cognitive as well as affective appraisals. Satisfaction can be each evanescent and steady via time. Life delight is the diploma to which a individual positively evaluates the usual first-rate of his/her life as-a-whole. In other words, how a great deal the individual likes the life he/she leads? The notion of life pride denotes an universal comparison of existence ${ }^{2}$. Human lifestyles are turning into complicated and extra executed nowa-days. In present day society the wishes and requirements of the people are ever growing and changing and due to this, pride is now not derived due to incomplete fulfillment of their needs. Dissatisfied humans are in all likelihood to make a contribution very little in any cause ${ }^{3}$. Hurlock explains that life satisfaction is a condition regarding welfare or satisfaction which is a pleasant condition and arises when needs and expectations meet or can be fulfilled ${ }^{4}$.

Life satisfaction of a person is influenced through quite a number elements like age, education, occupation, healthstatus, household background, economic status, social participation, religions and enjoyment time activities. Age is one of the elements influencing existence satisfaction. Age of the respondents and period of the offerings usually go hand in hand. As age increases, an individual's experience capacities and training also will increase ${ }^{5}$. If a carpenter is satisfied with their job, he holds positive feeling about life. If a carpenter is not satisfied with their job, he holds negative feeling to their life.

${ }^{*}$ Author for correspondence 
Job delight is also viewed as a section of lifestyles satisfaction. The nature of a worker's environment of the job circuitously influences his or her emotions on the job. Similarly, due to the fact a job is a necessary section of existence for many workers, existence impacts work and work affects lifestyles ${ }^{6}$.

Life satisfaction becomes one of the important studies in positive psychology. Life pleasure has been conceptualized as one factor of individual subjective well-being. Life satisfaction has become one of the important aspects in an individual development, because of the many positive impacts that can result from life satisfaction felt by individuals ${ }^{7}$.

Need of lifestyles satisfaction entails normally the complete existence of a character and all the aspects of life. Life pride is the dominance of nice feeling to the negative ones in each day existence and capability to be true in different views such as happiness and moral ${ }^{8}$.

The learn about on existence pride is the need of the hour and is very outstanding attribute to be studied in today's traumatic life, without pride man cannot lead a peaceful and affluent life. So, one need to examine to damage tensions, worries and anxieties in each day life. Without lifestyles satisfaction, there is disharmony in the internal and outer self. It offers upward thrust to feeling of emptiness, uneasiness and meaningless in life. This paradoxical scenario leads to crisis of character, values and working efficiency. Life satisfaction includes the capability for enjoyment. The more we can revel in what we have, the happier we are. A person having high lifestyles delight is predicted to have glad adjustment with life and vice-versa ${ }^{9}$.

\section{Literature Review}

Many discussions and definitions of life satisfaction can be located as it is no longer a very easy to understand notion.

The comprehensive understanding of motivation factors that affected worker job pride in fixtures manufacturing. Questionnaire evaluation were selected as the key technique primarily based on the located data, pinnacle 10 motivators, which the personnel of fixtures manufacturing agencies relate as the most pleasant have been identified. According to respondents 3 most enjoyable factors included physical work demands. Outcomes resulted in a collection of pointers for the furniture manufacturing businesses to center of attention on in order to raise worker job pleasure with regards to the truth that only well-encouraged employees can make bigger the effectively of the total employer ${ }^{10}$.

Korkut studied the level of job satisfaction amongst employees. Job satisfaction stage of personnel working in furnishings enterprise measured by means of a survey method. The survey form consists of two sections. The first part includes questions regarding the demographic profile and $2^{\text {nd }}$ part includes questions related to the job satisfaction. Result of the lookup it used to be located the participants had been partly satisfied. Job delight stage of worker working for the fixtures enterprise demographic versions published that job pleasure did now not vary meaningfully according to versions such as gender, age, marital status, degree of schooling and expert experience of employees ${ }^{11}$.

This research, which was once focused on relationship between job and lifestyles satisfaction. A survey find out about is carried out to find out relationship between job and lifestyles delight among the personnel of bank, colleges, schools and government/non-government organizations. Satisfactions with existence scale were used. Data exhibits that the employees of Kathmandu are comfortable in their job and life. Those employees who are very relaxed with their jobs had been discovered to be extra comfortable in their lifestyles ${ }^{12}$.

\section{Objectives of the Study}

The essential goal of the present research to find out about is to decide the life satisfaction amongst carpenters.

\section{Materials and Methods}

Snowball sample method was used. The present learn about was once performed in Lucknow city. The independent variables considered for this study had been age and kind of work. Data was collected from 120 male respondents. SWLS (Satisfaction with lifestyle scale) was used to collect information about life satisfaction among carpenters. SWLS was created by Diener, Emmons, Larsen and Griffin in 1985. The scale was developed as a way to assess an individual's cognitive judgment of their satisfaction with their life as a whole.

\section{Results}

The demographic profile, work profile of carpenters presented and discussed here. 
Table 1. Demographic Profile of Carpenters

\begin{tabular}{|c|c|c|c|}
\hline \multicolumn{2}{|c|}{ Demographic Profile } & Frequency $(\mathrm{N}=120)$ & Percentage (\%) \\
\hline \multicolumn{4}{|c|}{ Age (in years) } \\
\hline 1. & $20-30$ & 31 & 25.8 \\
\hline 2. & $30-40$ & 20 & 16.7 \\
\hline 3. & $40-50$ & 36 & 30.0 \\
\hline 4. & $50-60$ & 23 & 19.2 \\
\hline 5. & $60-70$ & 10 & 8.3 \\
\hline \multicolumn{2}{|r|}{ Total } & 120 & 100.0 \\
\hline \multicolumn{4}{|c|}{ Education } \\
\hline 1. & Illiterate & 38 & 31.7 \\
\hline 2. & Up to $10^{\text {th }}$ & 43 & 35.8 \\
\hline 3. & Up to $12^{\text {th }}$ & 20 & 16.7 \\
\hline 4. & Up to graduate & 19 & 15.8 \\
\hline \multicolumn{2}{|r|}{ Total } & 120 & 100.0 \\
\hline \multicolumn{4}{|c|}{ Marriage Status } \\
\hline 1. & Married & 98 & 81.7 \\
\hline 2. & Single & 22 & 18.3 \\
\hline \multicolumn{2}{|r|}{ Total } & 120 & 100.0 \\
\hline \multicolumn{4}{|c|}{ Family Type } \\
\hline 1. & Joint & 58 & 48.3 \\
\hline 2. & Nuclear & 62 & 51.7 \\
\hline \multicolumn{2}{|r|}{ Total } & 120 & 100.0 \\
\hline
\end{tabular}

Table no. 1 represent the demographic data and general information of carpenters. The table clearly indicates that the domain part (30\%) of the carpenters belongs to the 40-50 years age group, and least percentage (8.3\%) of carpenters belongs to 60-70 years age group. It is also evident from the data that $35.8 \%$ of the sample have education only up to $10^{\text {th }}$, and very less percentage (15.8\%) of the sample have studied up to graduate. The table also specify the total respondents in which maximum $81.7 \%$ were married and minimum $18.3 \%$ of the respondents were single. Almost equal percentage of the sample, $51.7 \%$ and $48.3 \%$, respectively were found to be living in nuclear family and joint family.

The association between life satisfaction and age of the respondents has been examined. The table no. 3 indicates that the carpenters close to their ideal maximum $(\mu=5.25)$ in 40-50 years age group and minimum $(\mu=5.03)$ in $20-30$ years age group. Carpenters life excellent condition was found maximum $(\mu=3.25)$ in $40-50$ years age group and minimum $((\mu=2.00)$ in $60-70$ years age group. The table indicates that carpenters most satisfy with their life $(\mu=2.50)$ in $40-50$ years age group whereas they have minimum satisfaction $(\mu=1.84)$ in 20-30 years age group. The table indicates that carpenters have gotten important things in their life maximum $(\mu=4.48)$
Table 2. Work Profile of Carpenters

\begin{tabular}{|c|c|c|c|}
\hline \multicolumn{2}{|c|}{ Occupational profile } & Frequency $(\mathrm{N}=120)$ & Percentage (\%) \\
\hline \multicolumn{4}{|c|}{ Working duration of respondents } \\
\hline 1. & 4-6 hour & 25 & 20.8 \\
\hline 2. & 6-8 hour & 76 & 63.3 \\
\hline 3. & 8-10 hour & 19 & 15.8 \\
\hline 4. & $>10$ hours & 0 & 0 \\
\hline \multicolumn{2}{|r|}{ Total } & 120 & 100.0 \\
\hline \multicolumn{4}{|c|}{ Type of work } \\
\hline 1. & Roofer & 13 & 10.8 \\
\hline 2. & Framer & 61 & 50.8 \\
\hline 3. & $\begin{array}{c}\text { Cabinet } \\
\text { Maker }\end{array}$ & 46 & 38.3 \\
\hline \multicolumn{2}{|r|}{ Total } & 120 & 100.0 \\
\hline \multicolumn{4}{|c|}{ Breaks during work in a day } \\
\hline 1. & $<1$ & 0 & 0 \\
\hline 2. & $1-2$ & 79 & 65.8 \\
\hline 3. & $2-3$ & 41 & 34.2 \\
\hline 4. & $>3$ & 0 & 0 \\
\hline \multicolumn{2}{|r|}{ Total } & 120 & 100.0 \\
\hline \multicolumn{4}{|c|}{ Type of break } \\
\hline 1. & Toilet break & 47 & 39.2 \\
\hline 2. & Tea break & 26 & 21.7 \\
\hline 3. & Lunch break & 47 & 39.2 \\
\hline \multicolumn{2}{|r|}{ Total } & 120 & 100.0 \\
\hline \multicolumn{4}{|c|}{ Holidays (in month) } \\
\hline 1. & $<2$ days & 0 & 0 \\
\hline 2. & 2-4 days & 76 & 63.3 \\
\hline 3. & 4-6 days & 38 & 31.7 \\
\hline 4. & $>6$ days & 6 & 5.0 \\
\hline \multicolumn{2}{|r|}{ Total } & 120 & 100.0 \\
\hline \multicolumn{4}{|c|}{ Place of work } \\
\hline 1. & Shop & 107 & 89.2 \\
\hline 2. & Home & 13 & 10.8 \\
\hline \multicolumn{2}{|r|}{ Total } & 120 & 100.0 \\
\hline
\end{tabular}

The table no. 2 represent the occupational profile of carpenters. Table clearly shows that major parts (63.3\%) of the workers were working for 6-8 hours and least (15.8\%) were working for 8-10 hours in a day. The table shows that maximum $(50.8 \%)$ workers were framer and minimum $(10.8 \%)$ carpenters were roofer. Majority of the carpenters (65.8\%) take 1-2 breaks in a day whereas $34.2 \%$ carpenters were found to take $2-3$ breaks in a day. Maximum (63.3\%) carpenters were taking 2-4 days holidays in a month and minimum (5\%) respondents were in a habit of taking $>6$ days holiday in a month. The table also shows maximum (89.2\%) carpenters were working in shop, whereas minimum (10.8\%) were working in home. 
Table 3. Assessment of Life Satisfaction of Carpenters

\begin{tabular}{|l|c|c|c|c|c|c|c|c|}
\hline \multirow{2}{*}{ S. No. } & \multicolumn{7}{|c|}{ Age } & \multicolumn{2}{|c|}{} \\
\hline \multirow{2}{*}{ LIFE SATISFACTION } & $20-30$ Year & $30-40$ Year & $40-50$ Year & $50-60$ Year & $60-70$ Year & TOTAL & F- Value & P- Value \\
\cline { 2 - 8 } & Mean+SD & Mean+SD & Mean+SD & Mean+SD & Mean+SD & Mean+SD & .189 \\
\hline Life close to ideal & $5.03+.605$ & $5.05+.394$ & $5.25+.439$ & $5.04+.209$ & $5.00+.000$ & $5.10+.438$ & 1.563 & 5.288 \\
\hline $\begin{array}{l}\text { Excellent condition } \\
\text { of life }\end{array}$ & $3.00+1.238$ & $3.20+1.152$ & $3.25+1.180$ & $2.26+.689$ & $2.00+.000$ & $2.88+1.139$ & .001 \\
\hline Satisfied with life & $1.84+.374$ & $2.15+.671$ & $2.50+.878$ & $2.09+.417$ & $2.00+000$ & $2.15+.657$ & 5.101 & .001 \\
\hline $\begin{array}{l}\text { Gotted all important } \\
\text { things }\end{array}$ & $2.68+1.956$ & $4.00+1.806$ & $4.00+1,757$ & $4.48+1.310$ & $1.70+2.214$ & $3.56+1.957$ & 6.978 & .000 \\
\hline $\begin{array}{l}\text { I would change almost } \\
\text { nothing }\end{array}$ & $2.61+1.476$ & $3.30+1.593$ & $4.08+1.402$ & $4.74+.864$ & $5.00+.000$ & $3.78+1.547$ & 12.468 & .000 \\
\hline
\end{tabular}

in $50-60$ years age group and minimum $(\mu=1.70)$ in $60-70$ years age group. The table also indicates that carpenters would change almost nothing is maximum $(\mu=5.00)$ in $60-70$ years of age group and while it shows minimum change $(\mu=2.61)$ in 20-30 years age group, Life satisfaction depends upon the age of workers as soon as the age changes all values are varying.

The above table 4 indicates the type of work on life satisfaction. The association between life satisfaction and kind of work of the carpenters has been examined. The table indicates that the carpenters close to their ideal was highest $(\mu=5.26)$ in cabinet maker and least $(\mu=5.00)$ in roofer and framer. This data was found to be highly significant. The table indicated that carpenter's life excellent condition maximum $(\mu=3.17)$ in cabinet maker and minimum $(\mu=2.00)$ in roofer. The table indicates that carpenters satisfied with their life maximum $(\mu$ $=2.39)$ in cabinet maker and minimum $(\mu=2.00)$ in roofer and framer. The table also shows that carpenters have gotten

Table 4. Evaluation of Life Satisfaction of Carpenters According to Kind of Work

\begin{tabular}{|c|c|c|c|c|c|c|}
\hline \multirow{3}{*}{$\begin{array}{l}\text { S. No } \\
\text { LIFE SATISFACTION }\end{array}$} & \multicolumn{4}{|c|}{ Type of Work } & \multirow{3}{*}{ F- Value } & \multirow{3}{*}{ Sig. } \\
\hline & \multirow{2}{*}{$\begin{array}{l}\text { ROOFER } \\
\text { Mean+ SD } \\
\end{array}$} & \multirow{2}{*}{$\begin{array}{l}\text { FRAMER } \\
\text { Mean+ SD } \\
\end{array}$} & \multirow{2}{*}{$\begin{array}{c}\text { CABINET } \\
\text { MAKER } \\
\text { Mean+SD }\end{array}$} & \multirow{2}{*}{$\begin{array}{c}\text { TOTAL } \\
\text { Mean+ SD }\end{array}$} & & \\
\hline & & & & & & \\
\hline Life close to ideal & $5.0+.000$ & $5.0+.000$ & $5.26+6.81$ & $5.10+.438$ & 5.411 & .006 \\
\hline Excellent condition of life & $2.00+.000$ & $2.85+.997$ & $3.17+1.338$ & $2.88+1.139$ & 5.874 & .004 \\
\hline Satisfied with life & $2.00+.000$ & $2.00+.000$ & $2.39+1.022$ & $2.15+.657$ & 5.411 & .006 \\
\hline Gotted all important things & $5.00+.000$ & $3.25+2.216$ & $3.57+1.834$ & $3.56+1.957$ & 4.565 & .012 \\
\hline I would change almost nothing & $5.00+.000$ & $3.72+1.496$ & $3.50+1.683$ & $3.78+1.547$ & 5.177 & .007 \\
\hline
\end{tabular}

important thing in life maximum $(\mu=5.00)$ in roofer and minimum $(\mu=3.25)$ in framer. The table also indicate that the carpenters would change almost nothing in life maximum $(\mu=$ 5.00 ) in roofer and found minimum in framer. As per the data includes in table no. 4 were found to be major which shows the authentic result. So, the research shows that life satisfaction differs as type of work changes.

\section{Discussion}

The aspire of the present study to ascertain the age and kind of work affects the life satisfaction of the carpenters. The result of the present study examine life satisfaction depends on the age and type of work of carpenters. Final results were found in a study that carpenters satisfy with their work and life in 40-50 years age group. A comparative result were found in this study according to type of work, cabinet maker more satisfy with their work and his life style situation excellent. The result suggests that cupboard maker was highly satisfied with their life compare to roofer and framer. In 2014, Niharika and U.V. kiran given a noticeable result about it, that existence delight among bank personnel notably differs according to type of work $^{1}$. One another study, shows that these personal who are very pleased with their jobs have been determined to be more blissful in their lifestyles ${ }^{12}$.

In 2019, Korkut S., et al. also mentioned job delight stage of employee working for the fixtures enterprise demographic versions printed that job satisfaction did not 
range meaningfully in accordance to gender, age, marital status, working hours, level of education and expert journey of employees $^{11}$. In another study, shows that lifestyles satisfaction can be influenced with the aid of gender and high work load as well as degree of their income ${ }^{13}$.

\section{Conclusion}

The learn about is concluded by using the fact that humans observes common stage of existence satisfaction at all age tiers and its considered that as increase in age, the overall lifestyles pride decreases, with recognize to an extend in individual's income, the existence pleasure of carpenters additionally increases. The lifestyles pleasure influenced by a number of components social, economic, household and bodily factors. Based on observation, it is observed that there is a enormous distinction between the life delight of carpenters in accordance to age and kind of work. The satisfaction of the life of the carpenters working in a cabinet making is high. Findings of this study indicate that the carpenters of the Lucknow city are satisfied in their life and work. Dissatisfaction with work negatively affects person's health and happiness. So, carpenters select type of work in carpentry compatible with their interest. It can be concluded that there is a scope for enhancement in life delight from the ergonomic point of view training and focus programme for instructing the wood workers. Life pride is also regarded as a phase of job satisfaction. Life satisfaction is an essential phase of lifestyles for workers, lifestyles satisfaction influences work and work impact lifestyles pride.

\section{References}

1. Niharika and Kiran U.V. (2014). "Life satisfaction among bank employees." Int. J. Sci. Res. 3-6.
2. Singh, S.K. (2014). "Life satisfaction and stress level among working and non-working women” Int. J. Indian Psychol., 01-04.

3. Chahal, A., Chahal, S., Chowdhary, B., Chahal, J. (2013). "Job satisfaction among bank employee: An analysis of the contributing variables towards job satisfaction." Int. J. Sci. Res. 2-8.

4. Hurlock, E. B. (2009), Psikologiperkembangan, Jakarta: Erlangga.

5. Niwas, R., Jaidka, M.L., Sehgal, H. (2015). "Life satisfaction among rural and urban school teachers of Punjab in relation to their teaching attitude" Int. j. innov. pract. appl. res. 3-8.

6. Banerjee S. (2015). "A study of the relationship between job satisfaction and life satisfaction". Int. j. bus. quant. economics appl. manag. res. 1-8.

7. Qudsyi, h., Sholeh, A., Afsari, N., (2019). "Life satisfaction among college students: The role of self-monitoring through peer education." Advance in social science, education and humanities research, 399.

8. Cummins, R.A., and Nistico, H. (2002). Maintaining life satisfaction: The role of positive cognitive bias. J. Happiness Stud. Page no. 37-69. https://doi.org/10.1023/A:1015678915305

9. Kumari, R., (2020). "Life satisfaction is correspondence with self - efficacy among banking sector employee: A study of Sitamarhi district, North Bihar" Saudi J. Humanities Soc. Sci. https://doi. org/10.36348/sjhss.2020.v05i11.003

10. Lorincova, S., Schmidtova, J., and Javorcikova, J., (2016). "Employee job satisfaction in furniture manufacturing companies in the Slovak republic".

11. Korkut, S., D., Gedik, T., and Cagan, F., (2019). "Research on job satisfaction level of employees in the furniture industry, Turkey" Istanbul University, Page no. 124-132. https://doi.org/10.26650/ forestist.2019.19010

12. Mishra, K., (2021). "Relationship between job satisfaction and life satisfaction among the employees of Kathmandu, Nepal.

13. Mirfarhadi, N., Moosavi, S., and Tabari, R., (2013). "Life satisfaction and its determinants: a survey on Iranian nurses' population". J. Paramed. Sci., 4: ISSN 2008-4978. 